\title{
The Application of the Contingency Model and Soft Systems Methodology to Reconstruct the Intergovernmental Transfer System: Lessons Learned from the Implementation of Accrual- Based Accounting in Indonesia
}

\author{
Arifudin Miftakhul Huda ${ }^{1}$, Deddi Nordiawan ${ }^{2 *}$ \\ ${ }^{1}$ Magister of Accounting, Faculty of Economics and Business, Universitas Indonesia, Jakarta 10430, Indonesia \\ ${ }^{2}$ Department of Accounting, Faculty of Economics and Business, Universitas Indonesia, Depok 16425, Indonesia \\ *deddinordiawan@yahoo.com
}

\begin{abstract}
Indonesia has implemented an intergovernmental transfer system since 1999, in order to achieve financial balance in governmental entities. When accrual-based accounting was introduced to governmental entities, the intergovernmental transfer system experienced some problematic situations. This research aims to reconstruct Indonesia's intergovernmental transfer system in order to implement accrual-based accounting. The study structured the problematic situations in that system using the contingency model ${ }^{1}$. The study found that the implementation of accrual-based accounting in the intergovernmental transfer system can be stimulated by the setting of governmental accounting standards, which affects the expectation of the users of information, and the behavior of producers of information. Those expectations and behaviors are also affected by the basic attitudes of the users and producers of information, which will raise the need for accrual information. That expectation will encourage the implementation of accrual-based accounting by the producers of information. Furthermore, the implementation of accrual-based accounting faces some implementation barriers, such as organizational characteristics, qualifications of accountants, and size of jurisdiction. This research recommends reconstructing the intergovernmental transfer system using the soft systems methodology (SSM) ${ }^{2}$, for which the steps are formulating the conceptual model, discussing the model, and redefining it or taking action to improve it. In addition, this research recommends the reformulation of the allocation system. This research also initiated some outputs to support the implementation of these recommendations. The results of this research are very important for two main reasons. First, this research showed that there are significant benefits from the application of the contingency model and SSM with respect to reconstructing public policy in the context of financial-management reforms. Second, this research created a framework that guides the government to reconstruct its intergovernmental transfer system.
\end{abstract}

Keywords: Accrual-based accounting, contingency model, intergovernmental transfer, soft systems methodoloy.

\section{INTRODUCTION}

The audit report of the Audit Board of Indonesia (ABI) for the financial statement of the central government of Indonesia in 2015 states that there were problems in accounting policy and revenue/expense recognition that needed to be solved in order to implement accrual-based accounting to a sufficient degree. The intergovernmental transfer system also faces this problem. Whereas, Governmental Accounting Standards (GAS) has mandated the implementation of accrual-based accounting since $2015^{3}$.

The accounting policies of the central government and local government have not implemented accrual-based accounting in intergovernmental transfer system to a sufficient degree. They still implement cash-based accounting with some accrual adjustments at the end of the year to adjust underpayments or overpayments from the central government.

The implementation of accrual-based accounting in governmental accounting gives many benefits. Accrualbased accounting can provide informative and comprehensive information ${ }^{4-6}$.

The implementation of accrual-based accounting can be defined as innovation in governmental accounting ${ }^{1,7,8}$. The best example of implementing accrual-based accounting is in accounting for non-exchange transactions; this is because the concept of comparing cost against revenue cannot be applied to that type of transaction ${ }^{4,9,10}$. International Public Sector Accounting Standards (IPSAS) 23 sets the framework of accounting for non-exchange transactions. The intergovernmental transfer is an example of a non-exchange transaction ${ }^{11}$.

The implementation of accrual-based accounting in the intergovernmental transfer system faces problematic situations that are very complex. Because of these problematic situations, the research question of this research is "How can the intergovernmental transfer system be reconstructed in order to implement accrual-based accounting 
using the contingency model and the soft system methodology (SSM)?” This research aims to reconstruct the intergovernmental transfer system in order to implement accrual-based accounting.

\section{LITERATURE REVIEW}

\subsection{Contingency Model for Governmental Accounting Innovations}

New Public Management (NPM) drives innovations in governmental accounting ${ }^{4,12}$. Those innovations are in the form of implementation of accrual-based accounting ${ }^{3}$. Accrual-based accounting provides a more informative accounting system. The governmental accounting innovations can be explained using the contingency model ${ }^{1}$. This model has been applied by many researchers, $4,8,13-15$.

The contingency model contains four modules; these are (1) stimuli, (2) social structural variables, (3) structural variables of the politico-administrative system, and (4) implementation barriers. This model is demonstrated by Figure $1^{1}$.

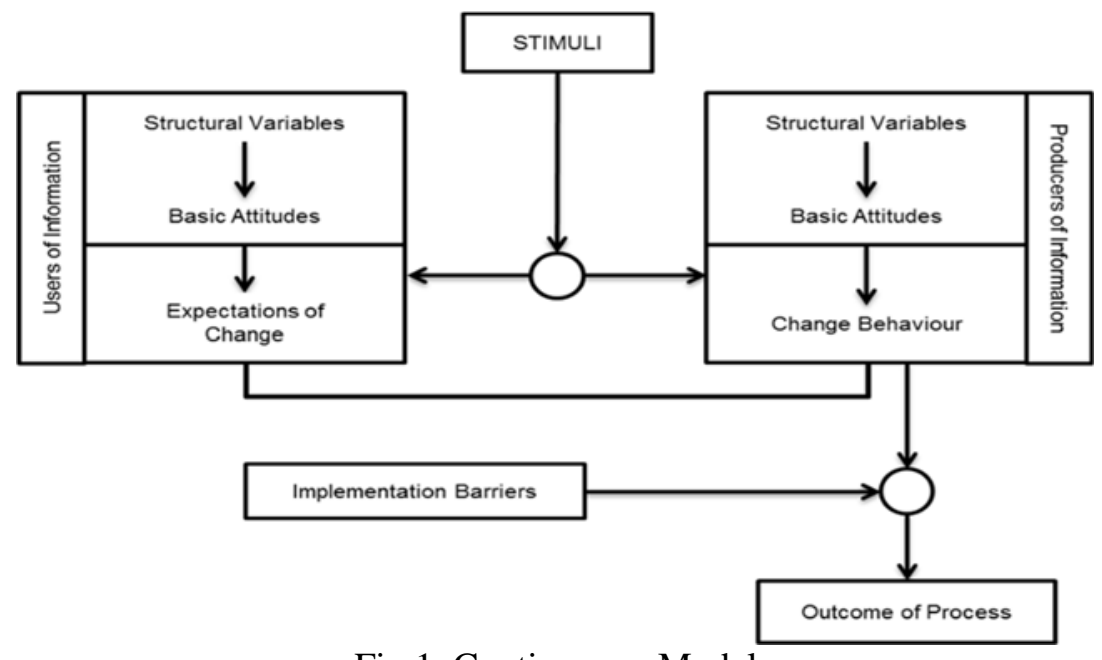

Fig.1. Contingency Model

Source: Luder (1992, Edited) ${ }^{1}$

\subsection{Accounting for Intergovernmental Transfers}

An intergovernmental transfer is one kind of non-exchange transaction; it is a transaction in which the receiver of the resources does not give consideration, directly or indirectly, to returns other than taxes ${ }^{10}$. The majority of governmental revenue is derived from non-exchange transactions ${ }^{10}$.

An entity recognizes assets, liabilities, and/or revenues from transfer when (a) the entity has an enforceable claim and (b) the entity assesses that the inflow of resources is probable. Its assessment of the probability is based on past experiences ${ }^{4,9,10,16}$.

\section{RESEARCH METHOD}

This research took a case-study approach regarding the phenomena in the intergovernmental transfer system. The units of analysis in this study are the Ministry of Finance (MoF) as the central government, the Directorate General of Fiscal Balance (DGFB) as the transferor entity, and three local governments as the receiver entities: the Provincial Government of the Special Capital Territory of Jakarta (Gov. of Jakarta), the Government of the City of Bekasi (City of Bekasi), and the Government of Bekasi Regency (Bekasi Regency). These three local governments were chosen by using clustering random sampling. The clusters were the provincial governments represented by the Gov. of Jakarta, the government of cities represented by the City of Bekasi, and regency governments represented by Bekasi Regency.

The contingency model was chosen to map the problematic situations because this model can explain the governmental-accounting-innovations process ${ }^{1}$. The implementation of accrual-based accounting is one kind of governmental accounting innovation ${ }^{7}$.

SSM was chosen to formulate the recommendations because this methodology aims to solve the problematic situations in human-activity systems. Problematic situations in the intergovernmental transfer system and its complexity are based on a human-activity system, so SSM is appropriate for use in this research. Moreover, the researchers have an actuality in intergovernmental system ${ }^{17}$. SSM is a learning cycle that consists of four activities: (1) determining the problematic situations, (2) forming conceptual models, (3) using the conceptual models in discussions, and (4) defining or taking action to improve the system ${ }^{2}$. The first step of SSM was replaced by the contingency model to structurize the problematic situations. 


\section{RESULTS AND DISCUSSIONS}

\subsection{Determining the Problematic Situations}

The structurization of the problematic situations in the intergovernmental transfer system was completed by using the contingency model. This research did some in-depth interviews, participative observations, and document analysis.

The DGFB and Bekasi Regency have implemented cash-based accounting for intergovernmental transfers with accrual adjustments for postponed transfers, and underpayments or overpayment at the end of the year. Gov. of Jakarta and City of Bekasi have implemented accrual-based accounting for intergovernmental transfers, but their accounting policies are still cash based with accrual adjustments at the end of the year. The contingency model is used to explain these implementations of the accounting bases.

Stimuli: The implementation of accrual-based accounting for intergovernmental transfers is stimulated by the setting of GAS. These standards are regulated by Government Regulation Number 71/2010. This stimulus can be considered to be a coercive isomorphism ${ }^{18}$. The stimulus will affect the expectations of the users of information and the behavior of the producers of information.

Social Structural Variables: These variables are related to the users of information ${ }^{1}$. Citizens have no or a small role as users of information ${ }^{15}$, so this research defines the budgeting division as the users of information. Therefore, socioeconomic status becomes irrelevant to this research. This research discusses political culture in the budgeting process. The political culture of the budgeting process affects the basic attitudes of users of information and changes their expectations. The budgeting division of the DGFB does not consider that the information in the financial statement for intergovernmental transfers (FSIT) is necessary. In contrast, the budgeting divisions in local governments use the information from the FSIT for budget formulation, although the expectations are different among the local governments. Those expectations will change the behavior of the producers of information in terms of whether they will or will not implement accrual-based accounting for intergovernmental transfers.

Structural Variables of the Politico-Administrative System: These variables are related to the producers of information. Staff training and recruitment are related to the number of accountants in the accounting unit ${ }^{1}$. Units with fewer accountants tend to implement cash-based accounting for intergovernmental transfers, while units with more accountants tend to implement accrual-based accounting for intergovernmental transfers. All units of analysis have an administrative culture that supports openness and staff participation. A checks-and-balances mechanism between legislative and executive also exist in all units.

The stimuli and structural variables for users and producers of information affect the behavior of producers of information. The accounting units of the Gov. of Jakarta and City of Bekasi believe that it is necessary to implement accrual-based accounting for intergovernmental transfers. In contrast, the accounting units of the DGFB and Bekasi Regency do not consider that it is necessary to implement accrual-based accounting for intergovernmental transfer. The reasons why they do not implement accrual-based accounting are because (1) there is uncertainty in allocation and (2) there is a lack of synchronization between central and local governments in recognizing the transfer of payables/receivables.

Implementation Barriers: Organizational characteristics will inhibit the implementation of accrual-based accounting if the unit that formulates the accounting policy and accounting system is located outside the accounting unit. An insufficient number of accountants is another barrier to implementing accrual-based accounting. The DGFB has very large-sized jurisdiction because it manages the intergovernmental transfer system for the surrounding area of Indonesia. This large size is also a barrier to implementing accrual-based accounting ${ }^{1}$.

The mapping of problematic situations in the intergovernmental transfer system can be summarized using the contingency model. This is shown in Figure 2.

Based on the problematic situations as shown in Figure 2, this research formulated some recommendations to improve the intergovernmental transfer system using $\mathrm{SSM}^{2}$. The formulation of these recommendations is as follows. 


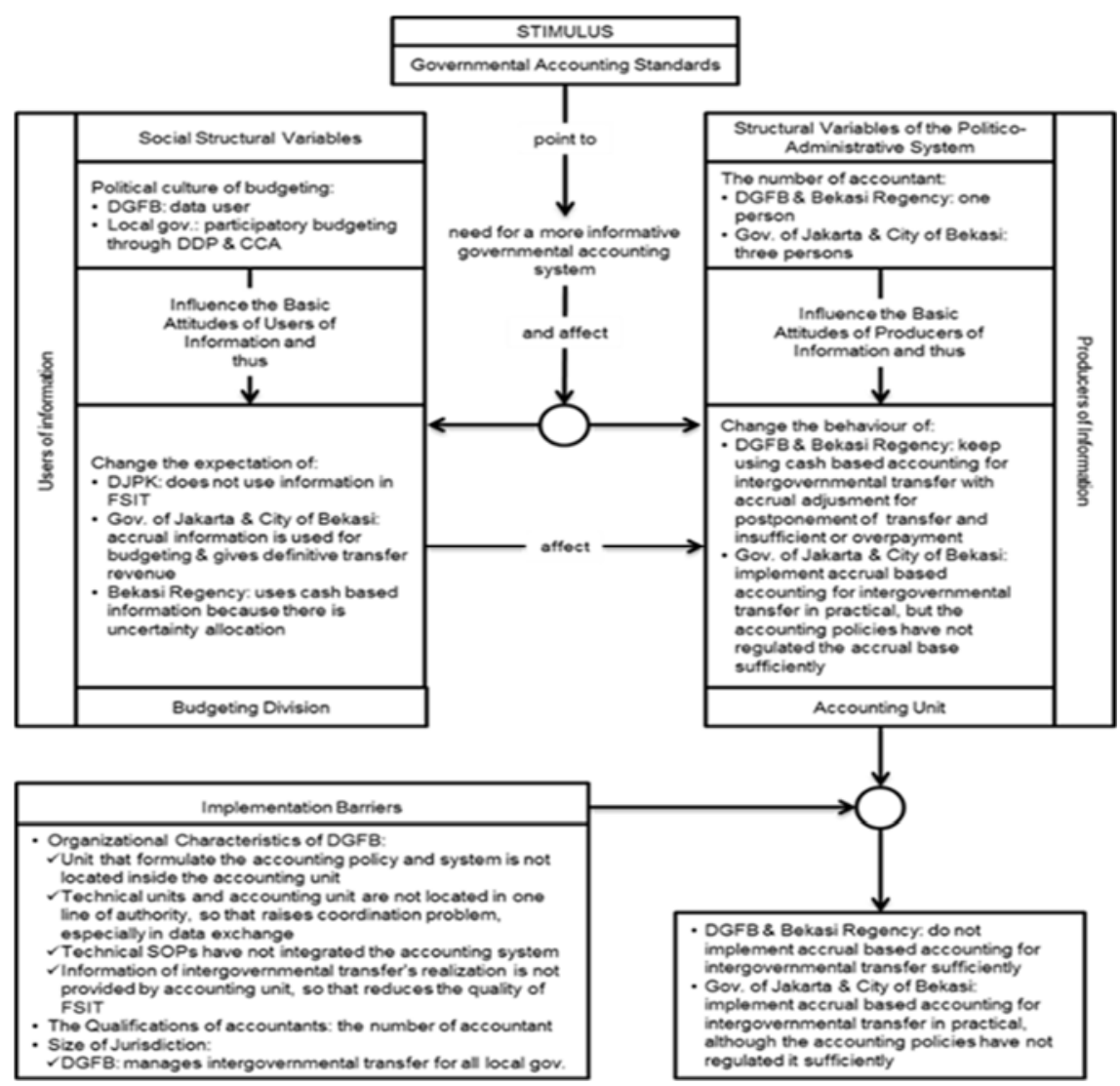

Fig.2. Problematic Situations in Intergovernmental Transfer System

\subsection{Formulating the Conceptual Models}

This research chose a root definition (RD) that was based on the problematic situations in Figure 2. This RD was used to form the conceptual model ${ }^{2}$, and represents the transformation in order to reconstruct the intergovernmental transfer system. The PQR formula (i.e., do P, by Q in order to achieve R) is used to determine the $\mathrm{RD}$, which is the allocation system that gives a definitive allocation by reformulating the revenue sharing to drive the implementation of accrual-based accounting for intergovernmental transfers. The RD aims to change the expectations of users of information and the behavior of producers of information, and reduce the implementation barriers $^{1}$, so that accrual-based accounting can be implemented in the intergovernmental transfer system.

The RD is tested using CATWOE (customers, actors, transformation, worldview, owners, and environment) analysis. The results of this analysis are shown in Table 1.

Table.1. CATWOE Analysis

\begin{tabular}{|l|l|}
\hline Customer & Government of Indonesia \\
\hline Actors & The heads of sub-directorates related to intergovernmental transfers in DGFB, and the head of the accounting unit in local governments. \\
\hline Transformation & $\begin{array}{l}\text { Revenue-sharing allocation is based on revenue realization in the current year } \rightarrow \text { revenue-sharing allocation was based on revenue } \\
\text { realization in the past two years. }\end{array}$ \\
\hline Worldview & Reconstruction of the intergovernmental transfer system is necessary to drive the implementation of accrual-based accounting. \\
\hline Owner & DGFB \\
\hline Environment & Budget, regulations, human resources, and sectoral ego. \\
\hline
\end{tabular}

Conceptual Model: Allocation System for Intergovernmental Transfers That Gives a Definitive Allocation.

This $\mathrm{RD}$ was chosen because it is the main reason why the budgeting division does not use the accrual information and the accounting unit has not implemented accrual-based accounting for intergovernmental transfers ${ }^{1}$. The uncertainty of allocation is caused by an allocation of revenue sharing that is changeable because it is based on revenue realization in the current year.

Revenue-sharing arrangements should be stable and predictable ${ }^{19-21}$. A definitive allocation can change the expectations of the budgeting division with regard to using accrual information, which encourages the accounting unit to implement accrual-based accounting for intergovernmental transfers ${ }^{1}$. A definitive allocation of revenue sharing can be achieved by reformulating the revenue-sharing base. Revenue sharing should be based on the revenue realization in the past two years, so the allocation can be definitive.

The definitive allocation of intergovernmental transfers enables central and local governments to recognize transfer expenses and revenue at the beginning of the year when Indonesian President's regulation for budget details has been issued. The Indonesian President's regulation is the arrangement that generates claims from local 
government at the beginning of the year and identifies the probable inflow of resources ${ }^{10,16}$.

Intergovernmental transfers can be categorized based on the existence and type of transfer requirements; they are (1) type 1, a transfer that has no requirements; (2) type 2, a transfer that has requirements for which the penalty is transfer postponement; and (3) type 3, a transfer that has requirements for which the penalty is transfer termination. Transfer postponement does not eliminate the local government's claim, but transfer termination does eliminate the local government's claim. Based on this classification, intergovernmental transfers of type 1 and type 2 can be recognized as expenses or revenue at the beginning of the year, but intergovernmental transfers of type 3 can be recognized as expenses and revenue when the local government has delivered the requirements correctly.

The next step was forming the conceptual model by amending the allocation system for intergovernmental transfers. This conceptual model is shown in Figure 3.

The conceptual model was used to construct a discussion in the real world in order to be able to apply the recommendations. The recommendations that were accepted in the discussion are (1) the allocation of revenue sharing is based on the revenue realization in the past two years; (2) transfer expenses/revenues for intergovernmental transfers of type 1 and type 2 are recognized at the beginning of the year when the Indonesian President's regulation about budget details is issued, and type 3 is recognized when the local government has delivered the transfer requirements correctly; and (3) the DGFB issues a formal document as a receipt of the transfer requirements from local governments.

Based on the recommendations, this research initiated output to be used as an implementation framework. The output is a draft of an accounting policy for the recognition of intergovernmental transfers. The draft of that accounting policy is as follows:

Transfer expenses/revenues are recognized at the beginning of the year when the Indonesian President's regulation for budget details has been issued for intergovernmental transfers of type 1 and type 2. In addition, transfer expenses/revenues for intergovernmental transfers of type 3 are recognized when the receipt for transfer requirements has been issued.

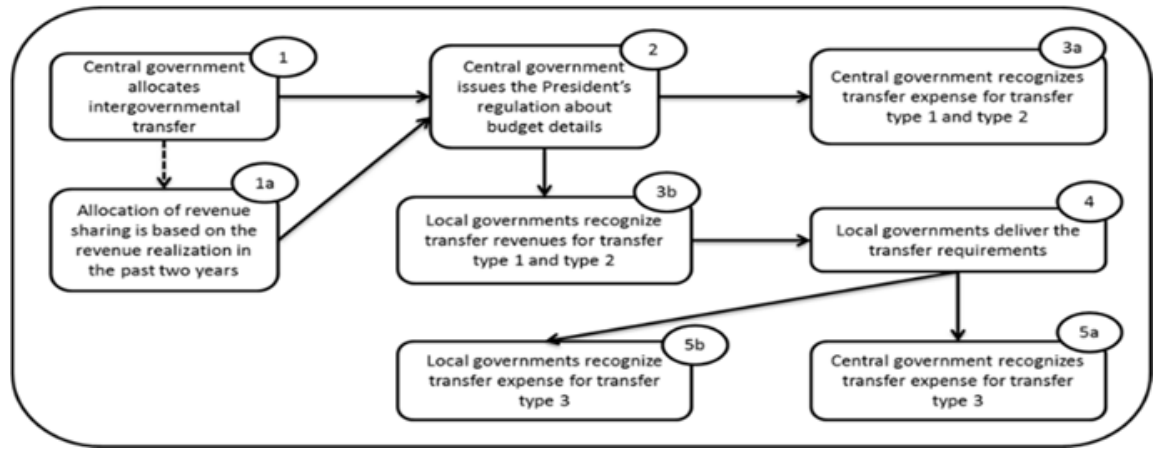

Fig. 3. Conceptual Model of RD

\section{CONCLUSION}

The problematic situations in the implementation of accrual-based accounting for intergovernmental transfers can be explained using the contingency model. The stimulus is the GAS, which affects the expectations of users of information and the behavior of producers of information. The expectations of users of information are influenced by the political culture of the budgeting process that creates a need for a more informative accounting system. This expectation changes the behavior of producers of information with respect to implementing accrual-based accounting for intergovernmental transfers. This behavior is also influenced by the number of accountants in the accounting unit. Moreover, the implementation of accrual-based accounting is also affected by implementation barriers, which are organizational characteristics, the qualifications of accountants, and the size of the jurisdiction.

Based on the problematic situations identified, this research formulated some recommendations using SSM, by reconstructing the intergovernmental transfer system that has been approved in order to support the implementation of accrual-based accounting for intergovernmental transfers. This research recommends that the allocation of revenue sharing is based on the revenue realization in the past two years.

This research has some limitations: (1) this research used only three local governments out of 542 local governments, (2) this research did not cover the transfer mechanism used by the State Treasury Service Office, and (3) the determination out process was limited to specific parties only.

\section{REFERENCES}

[1] K. G. Luder. A Contingency Model of Governmental Accounting Innovations in The Political-Administrative Environment. Research in Governmental and Nonprofit Accounting, Vol. 7 (1992): 99-127.

[2] P. Checkland, J. Pouter. Learning for Action: A Short Definitive Account of Soft System Methodology and its use for Practitioners, Teachers and Students, West Sussex: John Willey \& Sons, Ltd, 2006.

[3] Audit Board of Indonesia. Audit Report of Central Government' Financial Statement 2015: Audit Report of Internal Control System, 
Jakarta: Audit Board of Indonesia, 2016.

[4] F. Capalbo, M. Sorrentino. Cash to Accrual-based accounting: Does It Mean More Control for The Public Sector? The Case of Revenue from Non-Exchange Transactions. Risk Governance \& Control: Financial Markets \& Institutions, Vol. 3, Issue 4 (2013): 2835.

[5] A. Khan, S. Mayes. Transition to Accrual-based accounting, Washington, DC: International Monetary Fund, 2009.

[6] H. W. O. L. M. Korte. Dutch Central Government Budgeting and Accounting System. International Comparative Issues in Government Accounting, Ed. Aad Bac (2001): 9-18.

[7] J. L. Chan, R. H. Jones, K. G. Luder. Modeling Governmental Accounting Innovations: An Assessment and Future Research Directions. Research in Governmental and Nonprofit Accounting, Vol. 9 (1996): 1-19.

[8] E. Anessi-Pessina, G. Nasi, I. Steccolini. Accounting Innovations: A Contingent View on Italian Local Governments, Journal of Budgeting, Accounting \& Financial Management, 22 (2) (2010): 250-271.

[9] F. G. Grandis, G. Mattei. The Harmonization of Accounting in The Italian Public Sector: A New Accrual Basis Standard Versus IPSAS. Italian Journal of Public Law, Vol. 4, Issue 2 (2012): 376-398.

[10] K. Toudos, E. Poutos. Concept, Regulations and Institutional Issues of IPSAS: A Critical Review. European Journal of Business and Social Science, Vol. 2, No. 1 (2013): 43-54.

[11] International Public Sector Accounting Standards Board. Handbook of International Public Sector Accounting Pronouncements (2014 ed. Vol. I), New York: IFAC, 2014.

[12] N. Hyndman, C. Connolly. Accruals Accounting in The Public Sector: A Road Not Always Taken. Management Accounting Research, 22 (2011): 36-45.

[13] J. L. Chan. Accounting and Financial Management Reform in the United States Government: An Application of Professor Luder's Contingency Model, 1994.

[14] A. D. Godfrey, P. J. Devlin, M. C. Merrouche. A Diffusion-Contingency Model for Government Accounting Innovations. International Comparative Issues in Government Accounting, Ed. Aad Bac (2001): 279-296.

[15] M. Christensen. Accrual-based accounting in The Public Sector: The Case of The New South Wales Government. Accounting History, 7, 2, Accounting, Tax \& Banking Collection (2002): 93-124.

[16] L. Lorensen. Revenue Recognition in Government Accounting. Journal of Accountancy (pre-1986), 150, 000004, Accounting, Tax \& Banking Collection (1980): 105-109.

[17] D. Nordiawan, E. Prasodjo, S. Hardjosoekarto. Reconstruction of Performance-Driven Culture: Application of Soft Systems Methodology at East Java Province, Indonesia. Proceedings of the 16th European Conference on Research Methodology for Business and Management Studies, Dublin: Academic Conferences and Publishing International Limited, 2017. 277-287.

[18] P. J. DiMaggio, W. W. Powell. The Iron Cage Revisited: Institutional Isomorphism and Collective Rationality in Organizational Fields. American Sociological Review, Vol. 48 (1983): 147-160.

[19] S. Schiavo-Campo, P. Sundaram. To Serve and To Preserve: Improving Public Administration in A Competitive World, Manila: Asian Development Bank, 2001

[20] A. Shah. The Reform of Intergovernmental Fiscal Relations in Developing and Emerging Market Economies, Washington, D. C.: The World Bank, 1994

[21] R. Boadway, A. Shah (Ed.). Public Sector Governance and Accountability Series: Intergovernmental Fiscal Transfers: Principles and Practices, Washington, D. C.: The World Bank, 2007. 